\title{
Efeito da idade de desmame no desempenho reprodutivo de novilhas de corte expostas à reprodução aos 13/15 meses de idade
}

\begin{abstract}
Ricardo Zambarda Vaz ${ }^{1}$, José Fernando Piva Lobato
${ }^{1}$ Doutorando da Pós-Graduação em Zootecnia - Faculdade de Agronomia -UFRGS. Bolsista do CNPq

2 Departamento de Zootecnia - Faculdade de Agronomia - UFRGS. Bolsista CNPq. Caixa Postal 15100, CEP - 90.001-970, Porto Alegre, RS.

RESUMO - Este trabalho foi realizado com o objetivo de avaliar, por dois anos consecutivos, o efeito da idade de desmame no desempenho reprodutivo de 121 novilhas Braford acasaladas aos 13/15 meses de idade. Avaliaram-se duas idades de desmame - aos 77 dias pós-parto (desmame precoce); e aos 147 dias pós-parto (desmame convencional), utilizando-se 121 bezerras Braford nascidas nos anos de 2004 (66) e 2005 (55). Após o desmame, as bezerras foram mantidas, inicialmente, em pastagens cultivadas de verão (Pennisetum americanum, L.) e de inverno/primavera (Avena strigosa Schreb + Lolium multiflorum Lam). Foram avaliados o peso vivo (PV), a condição corporal (CC) e o ganho de peso médio diário (GMD) durante o período reprodutivo. O desmame precoce não ocasionou diferença significativa no peso ao início e ao final do período reprodutivo. As novilhas nascidas em 2005 apresentaram menor peso durante o período reprodutivo em relação às nascidas em 2004 . O ano influenciou a condição corporal ao início e ao final do período reprodutivo, que foi, respectivamente, 4,16 e 4,29 pontos para as novilhas nascidas em 2004; e 3,57 e 3,38 pontos para as nascidas em 2005. A porcentagem de prenhez não foi influenciada pela idade de desmame (55,5 e 70,7\% para novilhas do desmame precoce e as do desmame convencional, respectivamente) nem pelo ano (68,6\% para novilhas nascidas em 2004 e 57,6\% para as novilhas nascidas em 2005). As novilhas com diagnóstico de prenhez positivo tiveram maior desempenho reprodutivo durante a recria e o período de acasalamento em comparação àquelas com diagnóstico negativo. O desempenho reprodutivo das novilhas correlacionou-se positivamente com peso vivo e condição corporal ao início e ao final do período reprodutivo. O desmame precoce não afeta o desempenho reprodutivo de novilhas Braford aos 13/15 meses de idade.
\end{abstract}

Palavras-chave: Braford, condição corporal, desmame precoce, ganho de peso, prenhez

\section{Effects of the weaning age on the reproductive performance of beef heifers exposed to reproduction at 13/15 months old}

\begin{abstract}
The objective of the study was to evaluate, for two consecutive years, the weaning age effect on the reproductive performance of 121 Bradford heifers mated at 13/15 months old. Two weaning ages were assessed: at 77 days, early weaning (EW) or at 147 days, conventional weaning (CW). The heifers were born in 2004 (66) and 2005 (55). After weaning, heifers were kept initially on cultivated summer pasture (Pennisetum americanum, L.) and afterward on cultivated winter/spring pasture (Avena strigosa Schreb plus Lolium multiflorum Lam.). Live weight (LW), body condition (BC) and mean live weight gain (ADG) were evaluated during the mating period. Early weaning did not cause significant difference in weight at the beginning and end of the mating period. The heifers born in 2005 showed lower live weight during the mating than those born in 2004. The year influenced the body condition at the beginning and end of the mating that was, respectively, 4.16 and 4.29 points for heifers born in 2004, and 3.57 and 3.38 points for the ones born in 2005. Pregnancy rate was not affected by the heifer weaning age (55.5 and $70.7 \%$ for EW and $\mathrm{CW}$ heifers, respectively), nor by year ( 68.6 and $57.6 \%$ for heifers born in 2004 and 2005, respectively). Heifers that became pregnant had greater reproductive performance during the growing phase and mating period than those with negative diagnosis. The reproductive performance of the heifers was positively correlated with live weight and body condition at the beginning and end of the mating period. Early weaning did not affect the heifer reproductive performance at $13 / 15$ months old.
\end{abstract}

Key Words: body condition, Bradford, early weaning, pregnancy, weight gain

\section{Introdução}

Embora o Brasil detenha o maior rebanho bovino de corte comercial do mundo, com aproximadamente 169,9 milhões de cabeças (IBGE, 2006), os indicadores de produtividade deixam margem para significativos incrementos.

Práticas de manejo como o ajuste de carga animal, com consequente maior oferta de forrageira (Simeone \& 
Lobato, 1996, Fagundes et al., 2003), épocas de acasalamento e grupos raciais (Barcellos et al., 1997), e menores idades à desmama (Simeone \& Lobato, 1996; Lobato et al., 2000; Restle et al., 2001; Almeida \& Lobato, 2002) tem sido desenvolvidos com o objetivo de aumentar a produtividade dos rebanhos e a renda do produtor (Beretta et al., 2002).

Essas práticas, no entanto, precisam ser usadas em conjunto com práticas de gestão para diferentes categorias animais, pois sistemas intensivos de produção oferecem grande variedade de alternativas técnicas e econômicas a serem exploradas (Pötter et al., 2000; Beretta et al., 2001).

A redução da idade de desmame tem sido analisada e tem proporcionado significativos aumentos na taxa de prenhez de vacas (Moojen et al., 1994; Simeone \& Lobato, 1996; Restle et al., 2001; Almeida e Lobato, 2002), uma vez que zera os custos nutricionais da produção de leite (Restle et al. 2001) e do desmame à idade convencional, feito em torno dos 7 meses de idade do bezerro.

Em regimes intensivos de pecuária de corte, não somente os índices de prenhez são fundamentais para a maior produtividade (Pötter et al., 2000; Beretta et al., 2001), mas também a redução da idade de abate e de primeiro serviço das novilhas (Pötter et al., 2000; Beretta et al., 2002).

Desmames precoces não inviabilizam o abate de novilhos precoces aos 24 meses de idade (Restle et al., 1999a; Almeida et al., 2003; Lobato et al., 2007), aos 15 meses de idade (Pötter \& Lobato, 2003) nem o primeiro serviço aos 24 meses (Almeida \& Lobato, 2004). No entanto, são poucos os trabalhos experimentais em que bezerras desmamadas precoce ou convencionalmente são submetidas a recria objetivando o primeiro acasalamento entre 13 e 15 meses de idade.

Avaliou-se, por dois anos consecutivos, a influência da idade de desmame (desmame precoce ou convencional) sobre o comportamento reprodutivo de bezerras aos 13 e 15 meses de idade.

\section{Material e Métodos}

O experimento foi realizado na Granja Itú, município de Itaqui, fronteira oeste do Rio Grande do Sul, a latitude $29^{\circ} 12^{\prime}$ sul e longitude $55^{\circ} 36^{\prime}$ oeste, nos períodos reprodutivos de 2005-2006 e 2006-2007.

O relevo da região é ondulado, com coxilhas de solos profundos, naturalmente ácidos com textura superficial média, das unidades de mapeamento Júlio de Castilhos e Tupanciretã. O solo é classificado como latossolo vermelho podzólico(EMBRAPA, 1999) e o clima da região é subtropical, conforme classificação de Köppen (Moreno, 1961).
A avaliação foi realizada em um sistema de produção de ciclo completo, no qual as mães das bezerras foram distribuídas em: vacas com bezerras desmamadas precocemente ou vacas com bezerras desmamadas em idade convencional.

Utilizaram-se 121 bezerras Braford ( 76 e 45 bezerras de desmame precoce e convencional, respectivamente), nascidas na primavera de 2004 (7/9 a 15/10)e 2005(5/10 a 1/12), filhas de primíparas no primeiro ano e da repetição de prenhez destas primíparas no segundo ano, e desmamadas em média dos 77 dias de idade e $80,3 \mathrm{~kg}$ (desmame precoce), ou aos 147 dias de idade e $115,6 \mathrm{~kg}$ (desmame convencional).

As bezerras são filhas de oito touros Braford $5 / 8$ Hereford 3/8 Nelore, testados previamente para reprodução, durante os períodos reprodutivos de 2003/2004 e 2004/2005. Os touros foram os mesmos nos dois anos e manejados em esquema de rodízio a cada 15 dias. Nos anos de 2004 e 2005, as bezerras foram mantidas em pastagem nativa com suas mães até as idades de desmame, em carga animal de $320 \mathrm{~kg}$ de peso vivo/hectare, mas, no período reprodutivo de suas mães (10/12/2005 a 2/2/2006), as bezerras de 2005 foram mantidas com suas mães em pastagem de Brachiaria brizanta, cv Marandu, na carga de $1.115 \mathrm{~kg} / \mathrm{ha}$.

Por ocasião de seus desmames, as bezerras foram mantidas em mangueira por um período de 10 dias, com pastejos diários curtos a partir do quarto dia pós-desmame. As bezerras do desmame precoce foram mantidas durante o verão e outono em pastagem cultivada de milheto (Pennisetum americanum, L.) na lotação de 8 bezerras/ha e, nos meses de abril, pastejaram capim-braquiária (Brachiaria brizantha cv Marandu) na lotação de 4 bezerras/ha. No inverno e na primavera, pastejaram gramíneas cultivadas de aveia (Avena strigosa) e azevém (Lolium multiflorum Lam.) até o início dos períodos reprodutivos em 14/11/2005 (nascidas em 2004) e 24/11/2006 (nascidas em 2005). Durante o período de inverno no ano de 2004, nos meses de junho a agosto, as novilhas foram suplementadas com casquinha de soja na proporção de $0,4 \%$ do seu peso vivo médio.

Após a desmama convencional, as bezerras foram incluídas em pastagem de verão no mesmo grupo de manejo das bezerras desmamadas precocemente, onde permaneceram até o início do período reprodutivo. Todas as bezerras, após os desmames, receberam suplementação com $18 \%$ de proteína bruta e $75 \%$ de NDT, na quantidade de $1 \%$ do peso vivo, até o início do período de pastagem de inverno.

As estimativas da disponibilidade de forragem foram realizadas periodicamente, a cada 28 dias, acompanhando 
o desenvolvimento dos animais pelo método comparativo (Haydock \& Shaw, 1975). As amostras retiradas foram acondicionadas, identificadas e pesadas de acordo com o dia da coleta, para análise no Laboratório de Nutrição Animal da Faculdade de Agronomia da UFRGS. Os teores de proteína bruta $(\mathrm{PB})$ e fibra detergente neutro (FDN) das forragens foram estimados pelas técnicas descritas pela AOAC (1984) (Tabela 1).

Os animais foram pesados ao nascimento, a cada 28 dias e também ao início e final do período reprodutivo. Os ganhos de peso foram determinados pelas diferenças de peso entre pesagens, divididas pelo número de dias entre elas. Por ocasião das pesagens, foram realizadas as avaliações do escore de condição corporal, ECC (Lowman et al., 1973), atribuindo-se valores de 1 a 5 , em que $1=$ muito magra e 5 = muito gorda.

Os períodos reprodutivos de primavera/verão foram de 14/11/2005 a 23/1/2006 ( 70 dias) e de 24/11/2006 a 6/2/2007 (74 dias). O método reprodutivo foi o de monta natural, com touros previamente aprovados pelo teste da libido e por exame andrológico, na relação 1:25 touro/vaca. Para tanto, foram utilizados três e dois touros respectivamente, para os animais nascidos em 2004 e 2005. Os diagnósticos de gestação por ultrassonografia foram realizados 30 dias após o período reprodutivo.

Durante os períodos reprodutivos, os animais receberam mistura mineral de sal comum e ortofosfato bicálcico com $80 \mathrm{ppm}$ de fósforo. As vacinações contra febre aftosa e carbúnculo sintomático foram realizadas de acordo com o calendário e o manejo sanitário, procurando não prejudicar o desempenho animal.

O delineamento experimental foi o inteiramente casualizado, em arranjo fatorial $2 \times 2$, com duas idades de desmame e dois anos. Os resultados foram submetidos à análise de variância e ao teste $\mathrm{F}$ utilizando-se o seguinte modelo matemático:

$$
\mathrm{Y}_{\mathrm{ijkl}}=\mu+\mathrm{ID}_{\mathrm{i}}+\mathrm{A}_{\mathrm{j}}+\mathrm{ID}^{*} \mathrm{~A}_{\mathrm{ij}}+\mathrm{IN}_{\mathrm{k}}+\Sigma_{\mathrm{ijk} 1}
$$

em que: $\mathrm{Y}_{\mathrm{ijk}}=$ variáveis-dependentes (pesos e condições corporais ao início e ao final dos períodos reprodutivos, ganhos médios diários); $\mu$ =média de todas as observações;
$\mathrm{ID}_{\mathrm{i}}=$ efeito do i-ésimo idade de desmame, em que $\mathrm{i}=1$ (desmame precoce); 2 (desmame convencional); $\mathrm{A}_{\mathrm{j}}=$ efeito do j-ésimo do conjunto ano e idade da vaca; $I^{*} A_{i j}=$ efeito da interação i-ésimo idade de desmame $\times$ efeito do j-ésimo do conjunto ano e idade da vaca; $\mathrm{IN}_{\mathrm{k}}=$ covariável idade do animal de ordem $\mathrm{j} ; \Sigma_{\mathrm{ijk}}=$ Erro residual.

A idade da mãe das novilhas não foi incluída no modelo, pois está confundida totalmente com ano. Como o trabalho foi iniciado com vacas que pariram aos 3 anos (2004), e na sequência aos 4 anos (2005), esses dois efeitos estão totalmente confundidos e foram considerados como efeito conjunto de ano de nascimento da bezerra e idade da vaca.

As análises estatísticas para pesos e condição corporal foram realizadas usando o procedimento GLM do pacote computacional SAS, versão 6.08 (SAS, 1997), adotando-se $5 \%$ como nível de significância máxima para o teste $\mathrm{F}$. A porcentagem de prenhez nas duas idades de desmame foi analisada pelo teste do Qui-quadrado a 5\% de significância.

\section{Resultados e Discussão}

Não foi observada interação significativa entre idade de desmame e os anos de observação. Os dados serão discutidos analisando o sistema de produção no qual o estudo foi realizado.

A idade de desmame não influenciou $(\mathrm{P}>0,05)$ o peso ao início e final do período reprodutivo nem o ganho de peso nesse período (Tabela 2). Almeida \& Lobato (2004) também não observaram diferenças nos pesos ao início e final do acasalamento em novilhas de 26 meses de idade desmamadas aos 91 ou aos 170 dias de idade.

Os altos valores de FDN observados nas pastagens (Tabela 1) possivelmente influenciaram os baixos ganhos de peso durante os períodos reprodutivos. Conforme descrito por Van Soest (1994), alto teor de FDN limita o consumo de forragem pelos animais, pois está associado à ruminação, à taxa de passagem e ao consumo de alimento.

Pilau \& Lobato (2006) trabalharam na recria de bovinos com três níveis de suplementação em campo nativo $(0,7 ; 1,0$; e $1,3 \%$ do peso vivo) durante o período de maio a julho e,

Tabela 1 - Massa de forragem e percentuais de proteína bruta e fibra detergente neutro das pastagens utilizadas durante os períodos reprodutivos

\begin{tabular}{|c|c|c|c|c|c|c|c|}
\hline & \multicolumn{3}{|c|}{ Massa de forragem (kg/ha MS) } & \multicolumn{2}{|c|}{ Proteína bruta $(\%)$} & \multicolumn{2}{|c|}{ Fibra em detergente neutro $(\%$} \\
\hline & Período & Média & Variação & Média & Variação & Média & Variação \\
\hline Brachiaria brizanta & $\begin{array}{c}\text { Novembro } \\
\text { Fevereiro }\end{array}$ & 2.450 & $2350-2720$ & $\begin{array}{c}2005-2006 \\
6,95\end{array}$ & $6,57-7,17$ & 68,4 & $67,4-72,3$ \\
\hline Brachiaria humidicola & $\begin{array}{l}\text { Novembro } \\
\text { Fevereiro }\end{array}$ & 3.250 & $3030-3730$ & $\begin{array}{c}2006-2007 \\
6,52\end{array}$ & $5,91-7,38$ & 71,6 & $70,3-72,3$ \\
\hline
\end{tabular}


Tabela 2 - Pesos médios no início e final, ganho médio diário e idade inicial durante os períodos reprodutivos em cada idade de desmame e ano

\begin{tabular}{|c|c|c|c|c|c|}
\hline & № animais & Peso inicial (kg) & Peso final $(\mathrm{kg})$ & Ganho médio diário (kg) & II (dias) \\
\hline Desmame precoce & 76 & 272,1 & 297,0 & 0,365 & 397 \\
\hline Desmame convencional & 45 & 268,4 & 295,9 & 0,403 & 396 \\
\hline $2005 / 2006$ & 66 & $278,2 \mathrm{a}$ & $308,6 a$ & $0,472 \mathrm{a}$ & $413 a$ \\
\hline Média & & 270,3 & 296,5 & 0,384 & 398 \\
\hline $\mathrm{CV}(\%)$ & & 10,05 & 9,62 & 33,8 & 3,26 \\
\hline
\end{tabular}

a, $b$ médias na mesma coluna seguidas por letras diferentes diferem $(P>0,05)$ pelo teste $\mathrm{F}$.

CV - coeficiente de variação.

$\mathrm{II}=$ idade em dias.

posteriormente, com o uso de pastagem de aveia e azevém no período de julho a final de setembro e observaram ganhos médios diários de 0,359 e $0,820 \mathrm{~kg}$, respectivamente, na média dos níveis de suplementação. Nas avaliações periódicas das pastagens aparentemente consumidas pelos animais, verificaram ainda valores de 12 e $23 \%$ de PB e 73 e $43 \%$ de FDN, respectivamente, para pastagem nativa e cultivada.

O baixo ganho médio diário dos animais $(0,365 \mathrm{~kg}$ para o desmame precoce e $0,403 \mathrm{~kg}$ para o desmame convencional) é reflexo da baixa qualidade da pastagem. Além disso, esses animais tinham boa alimentação, pastagem cultivada de inverno, desde a desmama até o período pré-acasalamento. Animais que, depois de atingirem desempenho próximo do potencial ótimo, passam a ser mantidos sob condições de alimentação de baixa qualidade apresentam redução no ganho de peso (Allden, 1981).

Os ganhos médios diários das novilhas foram superiores aos relatados por Rocha et al. (2004) e Pilau \& Lobato (2008), que observaram perdas de pesos $-0,185 \mathrm{e}$ $-0,104 \mathrm{~kg} / \mathrm{animal} / \mathrm{dia}$, respectivamente, em bezerras expostas à reprodução entre os 13 e 15 meses de idade em pastagem nativa, depois de terem sido recriadas em pastagens cultivadas de inverno/primavera.

O ganho de peso antes e durante o período reprodutivo é fundamental no desempenho reprodutivo de novilhas, pois corresponde a um aporte de nutrientes adequado, que desencadeia a secreção e liberação de hormônios ligados à reprodução (Schillo, 1992). À medida que a novilha recebe maior aporte de proteína, e principalmente energia, os ciclos pulsáteis de hormônio luteinizante manifestam-se de forma mais intensa e em menor intervalo. Segundo Kinder et al. (1994), o hormônio luteinizante é limitante para o desencadeamento da puberdade em fêmeas bovinas.

$\mathrm{Na}$ literatura, os ganhos de peso durante os períodos reprodutivos variam muito com as condições de meio. No entanto, independentemente do ganho, o peso no início do período reprodutivo é fundamental em sistemas intensivos de pecuária de corte (Rovira, 1996; Rocha \& Lobato, 2002; Pilau \& Lobato, 2008).
Vaz \& Restle (2000ab) trabalharam com níveis crescentes de suplementação em campo nativo de novilhas dos 14 aos 17 meses de idade e verificaram aumentos lineares de ganho de peso e reflexos positivos na manifestação de estros e na porcentagem de prenhez com o aumento da suplementação. As novilhas sob suplementação tiveram ganhos de $0,727 \mathrm{~kg} /$ dia, próximos aos obtidos previamente em pastagens de inverno/primavera, de $0,700 \mathrm{~kg} / \mathrm{dia}$, enquanto aquelas sem suplementação, embora em campo nativo anteriormente roçado e diferido, tiveram ganho de $0,432 \mathrm{~kg} /$ dia.

O peso vivo de novilhas aos 14 meses de idade é influenciado pelo peso ao desmame e pelo nível alimentar no período pós-desmame e determina o ganho de peso neste período. Rocha \& Lobato (2002) e Pilau \& Lobato (2006) identificaram correlações positivas de novilhas concebendo entre 13 e 15 meses de idade com maiores pesos à desmama. De acordo com Wiltbank et al. (1985), além de bom peso à desmama, o peso vivo deve ser acompanhado por positivo e consistente ganho de peso em bezerras da desmama até o início do primeiro período reprodutivo.

Os pesos de 272,1 e $268,4 \mathrm{~kg}$ para as novilhas do desmames precoce e convencional, respectivamente, significam $60,1 \%$ do peso adulto do rebanho em estudo, no qual as vacas gordas para abate pesam em média $450 \mathrm{~kg}$. Segundo o NRC (1996), novilhas Bos taurus e Bos indicus devem ter no mínimo de 60 e $65 \%$ do seu peso adulto, respectivamente, para alcançar a puberdade e conceber.

Avaliando pesos-alvos para a manifestação da puberdade de novilhas submetidas a diferentes planos nutricionais pósdesmame e a influência da raça do pai, Weekley et al. (1993) obtiveram valor médio de $62,7 \%$ sobre o peso adulto do rebanho e $63,2 \%$ quando ajustados os valores para a raça Braford. Rocha \& Lobato (2002), trabalhando com novilhas Hereford e Braford também observaram a possibilidade de acasalamento entre 14 e 15 meses de idade, mesmo quando as novilhas apresentavam pesos médios $(240,2$ e $277,5 \mathrm{~kg}$, respectivamente) no início e final do período reprodutivo e alcançavam 59,39\% de prenhez média. 
Nos rebanhos comerciais muitas fêmeas de reposição possuem potencial genético para serem acasaladas entre 13 e 15 meses de idade, desde que utilizada alimentação diferente da tradicionalmente utilizada nos sistemas produtivos (Rocha \& Lobato, 2002; Pilau \& Lobato, 2006).

O peso ao início do período de reprodução é um bom indicativo do desempenho reprodutivo futuro (Beretta $\&$ Lobato, 1998; Rocha \& Lobato, 2002; Almeida \& Lobato, 2004). Entre os dois períodos de observação, os pesos ao início e ao final do período reprodutivo dos animais expostos à reprodução foram maiores na temporada 2005/ 2006, em decorrência da idade das novilhas, as quais, no período de serviço 2006/2007, são em média 25 dias mais novas (Tabela 2). Essa diferença ocorreu na sequência dos anos em sistemas produtivos de ciclo completo, em virtude do atraso da manifestação de cios pós-parto das vacas, que retardou as datas de partos futuros.

Independentemente da idade de desmame e do ano de observação (Tabela 3), a taxa de prenhez aumentou de acordo com o peso vivo, atingindo 94,74\% entre Novilhas pesando $305 \mathrm{~kg}$ ou mais. Rovira (1996) identificou respostas crescentes em fertilidade até os $300 \mathrm{~kg}$ de peso vivo em novilhas de raças britânicas ou suas mestiças acasaladas aos 14 meses de idade. Valores muito semelhantes, 93 e 88\%, foram observados por Funston \& Deustscher (2004) com novilhas com acasalamento na mesma idade e com pesos médios iniciais de 330 e $319 \mathrm{~kg}$, respectivamente.

Em estudo de probabilidade de prenhez para novilhas acasaladas entre 14 e 15 meses, Bittencourt et al. (2005) verificaram o peso ótimo de $338,8 \mathrm{~kg}$. Os resultados indicaram que $73,6 \%$ das variações na probabilidade de prenhez puderam ser explicadas pelo peso ao início do acasalamento. Contudo, resultados encontrados por Rocha \& Lobato (2002) indicam que as taxas de prenhez não estão associadas a taxas de crescimento ou pesos atingidos em idades fixas. Entretanto, Restle et al. (1999b), estudando os efeitos de grupo genético e heterose sobre a idade a puberdade de novilhas de corte Charolês, Nelore e cruzadas F1, concluíram que as novilhas mais pesadas ao desmame são as mais precoces na manifestação da atividade sexual.
Outro fator importante para o bom desempenho reprodutivo de novilhas aos 13/15 meses de idade é a condição corporal no início da estação reprodutiva, que não diferiu entre as idades de desmame, tanto no início como no final dos períodos reprodutivos (médias de 3,87 e 3,83 pontos, respectivamente), reflexo do desenvolvimento similar apresentado pelos dois grupos de animais.

O escore de condição corporal médio de 3,87 é alto e não é atributo limitante para o bom desempenho reprodutivo. Rovira (1996) recomenda, para bons níveis de concepção de novilhas entre 13 e 15 meses de idade, condição corporal mínima de 3,0 em escala de 1 a 5 pontos. A condição corporal média observada e analisada como característica isolada permite esperar bons desempenhos reprodutivos, no entanto muitas novilhas não tinham peso vivo adequado para concepção. No início dos períodos reprodutivos, $58,76 \%$ das novilhas estavam com peso dos $60 \%$ abaixo do peso adulto recomendável $(<275 \mathrm{~kg})$.

A superioridade em condição corporal das novilhas nascidas no ano de 2004 e acasaladas em 2005/2006 em relação às nascidas em 2005 e expostas à reprodução em 2006/2007 (4,16 e 3,57 pontos, respectivamente) deveu-se à suplementação durante a recria em pastagem de inverno/ primavera. O maior consumo de energia via suplemento proporcionou aumento da condição corporal.

$\mathrm{O}$ aumento do consumo de energia favorece o aumento dos níveis de glicose, insulina e IGF-I e permite maior número de ondas ovulatórias, uma vez que esses metabólitos são reguladores da atividade secretória hipotalâmicahipofisiária (Schillo, 1992). Aumentos significativos na condição corporal de novilhas acasaladas entre 13 e 15

Tabela 3 - Efeito do peso ao início do acasalamento sobre o percentual de prenhez aos 13/15 meses de idade

\begin{tabular}{ccc}
\hline Faixa de peso $(\mathrm{kg})$ & Número & Prenhez $(\%)$ \\
\hline$\geq 305$ & 19 & $94,74 \mathrm{a}$ \\
$290-304$ & 16 & $75,00 \mathrm{ab}$ \\
$276-289$ & 15 & $53,33 \mathrm{bc}$ \\
$261-275$ & 19 & $57,89 \mathrm{bc}$ \\
$\leq 260$ & 52 & $48,08 \mathrm{c}$ \\
\hline
\end{tabular}

a,b,c Médias na coluna seguidas de letras diferentes diferem $(\mathrm{P}<0,05)$ pelo teste qui-quadrado.

Tabela 4 - Condição corporal inicial e final dos períodos reprodutivos, de acordo com a idade de desmame e ano

\begin{tabular}{|c|c|c|c|}
\hline & Número de animais & Condição corporal inicial (pontos) & Condição corporal final (pontos) \\
\hline Desmame precoce & 76 & 3,83 & 3,81 \\
\hline Desmame convencional & 45 & 3,90 & 3,85 \\
\hline $2004 / 2005$ & 66 & $4,16 \mathrm{a}$ & $4,29 \mathrm{a}$ \\
\hline Média & & 3,87 & 3,83 \\
\hline CV (\%) & & 6,00 & 5,04 \\
\hline
\end{tabular}

a,b Médias na mesma coluna, seguidas por letras diferentes diferem $(\mathrm{P}<0,05)$ pelo teste $\mathrm{F}$.

CV - Coeficiente de variação. 
meses de idade também foram observados por Pilau \& Lobato (2006) e Vaz \& Restle, (2000a), respectivamente, em novilhas sob suplementação no período pré-acasalamento e no período reprodutivo.

Embora com pesos e condições corporais médias semelhantes, as novilhas do desmame convencional apresentaram maior taxa de prenhez em comparação às do desmame precoce: os percentuais de prenhez foram de 70,65 vs 55,55\% ( $\mathrm{P}>0,05)$, respectivamente. Essa diferença de 15,1 pontos percentuais $(\mathrm{P}<0,05)$ pode ter sido influenciada pela estrutura dos dados e pelo pequeno número de animais no estudo. Segundo Sampaio (1998), contingentes reduzidos de observações aumentam o intervalo de confiança dos resultados percentuais, equiparando indevidamente grupos com porcentagens muito diferentes.

De acordo com Byerley et al. (1987), novilhas acasaladas no terceiro ciclo estral apresentam melhor desempenho reprodutivo quando comparadas com novilhas acasaladas durante os ciclos iniciais da puberdade. Novilhas de reposição devem alcançar a puberdade cerca de 60 dias antes da estação de monta para terem condições de prenhez no início do primeiro período reprodutivo.

Novilhas prenhes no final do período reprodutivo apresentam menor produtividade e bezerros mais leves à desmama, quando a desmama é realizada em datas fixas e têm maior intervalo de partos em comparação a novilhas prenhes no início do período reprodutivo (Lesmeister et al., 1973).

Há variabilidade nos resultados de prenhez entre animais desmamados em diferentes idades, porém as diferenças não são significativas (Moraes \& Lobato, 1993; Albospino \& Lobato, 1993; Almeida \& Lobato, 2004). Embora a diferença também não tenha sido significativa $(\mathrm{P}>0,05)$, na média das duas temporadas, a taxa de prenhez entre as novilhas desmamadas à idade convencional foi $27,18 \%$ maior.

A redução na porcentagem de prenhez (Tabela 5) entre as novilhas nascidas em 2005 (57,55\%) deve-se, em parte, à diferença de idade dos animais no início do período de acasalamento, onde foram observadas médias iniciais de idades de 405 e 380 dias, respectivamente, para os anos de

Tabela 5 - Taxa de prenhez (\%) em novilhas de demame precoce e convencional acasaladas entre os 13 e 15 meses de idade

\begin{tabular}{lccc}
\hline & \multicolumn{2}{c}{ Ano de observação } & \multirow{2}{*}{ Média } \\
\cline { 2 - 3 } & $2005 / 2006(76)$ & $2006 / 2007(45)$ & \\
\hline Desmame precoce & $64,9(37)$ & $46,2(29)$ & 55,55 \\
Desmame convencional & $72,4(39)$ & $68,9(16)$ & 70,65 \\
Média & 68,65 & 57,55 & \\
\hline
\end{tabular}

$(\mathrm{P}>0,05)$.
2004 e 2005. Essa diferença de 25 dias é de grande importância, pois equivale a cerca de $6,25 \%$ do período de vida da novilha quando o acasalamento é feito próximo a um ano. $\mathrm{Na}$ comparação entre novilhas diagnosticadas como gestantes ou não gestantes, a idade ao início do período reprodutivo foi de 400 e 388 dias, respectivamente. Weekley et al. (1993) observaram idades à puberdade de 425 dias para novilhas filhas de touros Braford.

Trabalhos realizados no Clay Center-USA indicam resultados variados para a idade à puberdade de novilhas. Arije \& Wiltbank (1971) e Cundiff et al. (2000) em trabalho com novilhas Hereford, observaram idades à puberdade de 436,4 e 353 dias, respectivamente. Cundiff et al. (2000) verificaram, em novilhas Brahman, idades à puberdade de 411 dias, com interação entre o nível nutricional e a idade à puberdade, dificultando o isolamento dos fatores, pois a nutrição é o fator limitante e de maior importância econômica.

À medida que se intensifica o sistema de produção adotando o desmame precoce, o manejo nutricional se torna importante para aumentar o índice de prenhez (Lobato \& Barcellos, 1992; Moojen et al., 1994; Simeone \& Lobato, 1996; Restle et al., 2001). Diversos trabalhos comprovam a influência dos manejos nutricionais pré (Arije \& Wiltbank, 1971; Pattterson et al., 1992) e pós-desmame (Wiltbank et al., 1985) no desempenho reprodutivo de novilhas de corte acasaladas precocemente.

De acordo com o diagnóstico de gestação, independentemente da idade de desmame e do ano de observação, desde a idade do desmame precoce, houve diferenças no peso, nas taxas de ganhos de pesos médios diários e nos escores corporais entre novilhas que viriam a ficar prenhes ou não, embora não tenha ocorrido diferença $(\mathrm{P}>0,05)$ na idade em dias no início do período reprodutivo. Resultados semelhantes foram encontrados por Rocha \& Lobato (2002), que relataram que novilhas que não conceberam foram, desde a desmama até o final do acasalamento, significativamente mais leves. A diferença de peso médio no fim do período de acasalamento foi de $22,1 \mathrm{~kg}$ pró-novilhas gestantes, que corresponde a $7,7 \%$ a mais em peso vivo.

Fêmeas com menor peso à desmama poderiam receber um tratamento diferenciado, o que possibilitaria melhor condição de desenvolvimento corporal e maior probabilidade de prenhez (Pereira Neto \& Lobato, 1998; Beretta \& Lobato, 1998).

Não houve diferença nos ganhos de peso das novilhas nos períodos entre o desmame convencional e o início do acasalamento, bem como durante o acasalamento $(\mathrm{P}>0,05)$. Porém, ganhos de pesos significativos foram verificados 
Tabela 6 - Médias de peso, condição corporal, ganho de peso e idade de novilhas diagnosticadas como prenhes ou não-gestantes

\begin{tabular}{lcc}
\hline & Prenhes & Não-gestantes \\
\hline Novilhas desmame precoce (n) & 42 & 34 \\
Novilhas desmame convencional (n) & 32 & 13 \\
Peso (kg) & & \\
Nascimento & 27,83 & 27,96 \\
Desmame precoce & 83,45 & $77,11^{*}$ \\
Desmame convencional & 119,2 & $104,7 * *$ \\
Início do acasalamento & 278,8 & $257,9 * *$ \\
Final do acasalamento & 305,2 & $283,1 * *$ \\
Condição corporal (pontos) & & \\
Início do inverno & 2,78 & 2,71 \\
Início do acasalamento & 3,94 & $3,65 *$ \\
Final do acasalamento & 3,94 & $3,72 *$ \\
Ganho médio diário (kg/dia) & & \\
Nascimento ao desmame precoce & 0,722 & 0,768 \\
Nascimento ao desmame convencional & 0,621 & $0,570^{*}$ \\
Desmame precoce ao acasalamento & 0,488 & $0,452^{*}$ \\
Desmame convencional ao acasalamento & 0,621 & 0,592 \\
Início ao final acasalamento & 0,393 & 0,363 \\
Idade acasalamento, dias & 400 & 388 \\
\hline P $<0,05 ; * *$ P $<0,01$. & &
\end{tabular}

do nascimento até o desmame convencional entre novilhas prenhas e não prenhas ao final do período de acasalamento. Patterson et al. (1992) ressaltam a importância, para o acasalamento precoce de novilhas, do ganho de peso pré-desmame, Short \& Bellows (1971) evidenciaram que planos de nutrição baixa retardam a puberdade e o acasalamento de novilhas de corte.

Embora sem diferença $(\mathrm{P}>0,05)$, as novilhas diagnosticadas prenhes foram em média 12 dias mais velhas no início do período reprodutivo que aquelas que não conceberam. Rocha \& Lobato (2002) também verificaram maior taxa de concepção nas novilhas mais velhas ao início do período reprodutivo.

Ao se trabalhar com "sistema um ano", o número de novilhas necessárias para a reposição é inferior ao número total (Pötter et al., 1998), o que possibilita a eliminação do sistema de produção de novilhas que não concebem e maior eficiência produtiva e reprodutiva futura (Morris, 1980; Short et al., 1994), além de aumentar a taxa de desfrute (Pötter et al., 1998; Beretta et al., 2002).

Lobato \& Magalhães (2001) analisaram vacas primíparas aos 3 e 4 anos de idade e verificaram aumentos nos intervalos de partos $(\mathrm{P}<0,05)$ com o aumento da idade das vacas, que se manifestaram também na repetição de prenhez com taxas decrescente, porém não-significativa $(\mathrm{P}>0,05)$ de $91,1 \%$ e $86,2 \%$, respectivamente, para vacas paridas aos 3 e 4 anos. Esses autores concluíram que a idade tardia ao primeiro parto estaria relacionada à diferença genética para puberdade, ao pouco desenvolvimento das novilhas a idades menores. Todos esses fatores devem ser considerados na eliminação de novilhas que, tendo idade e peso, não conceberem.

Desta forma, o 'sistema um ano' não deve ser generalizado para todas as bezerras de reposição. Resultados de pesquisas brasileiras (Restle et al., 1999) comprovam a existência de novilhas aptas à reprodução em diferentes idades. De acordo com Fries (2003), a novilha deveria ser considerada subfértil ou infértil somente depois de falhar ao desafio quando exposta à reprodução considerando o sistema produtivo no qual está inserida. A diminuição da variabilidade entre indivíduos pode não interessar em rebanhos com sistema de seleção, mas, em rebanhos comerciais, a uniformidade da produção pode ser importante no resultado econômico final (Fries, 2004).

O peso vivo e a condição corporal correlacionaram-se entre si de forma significativa, tanto no início como no final do período reprodutivo (Tabela 7). Essas variáveis são importantes para o bom desempenho reprodutivo de novilhas acasaladas entre os 13 e 15 meses de idade (Rocha \& Lobato, 2002; Pilau \& Lobato, 2006). O peso ao desmame convencional das novilhas se correlacionou positivamente com os demais pesos e com a taxa de prenhez. Restle et al. (1999b) não encontraram associação entre o peso à desmama e o peso à puberdade das novilhas, porém observaram correlação - $0,39(\mathrm{P}<0,01)$ com a idade à puberdade, comprovando que novilhas mais pesadas ao desmame são mais precoces. Assim, segundo Patterson et al. (1992), o peso ao desmame tem maior importância em sistemas de pecuária de corte intensivos.

O desenvolvimento adequado de novilhas de reposição no 'sistema um ano' poderia ser importante para a garantia de índices de prenhez compatíveis com a pecuária intensiva, pois todas as variáveis estudadas tiveram correlação positiva com a taxa de prenhez das novilhas aos 13/15 meses de idade (Tabela 7). Embora essas correlações tenham tido níveis e significância elevada, foram de baixo valor para variáveis relacionadas à reprodução.

A taxa de prenhez média de $63,10 \%$ observada foi próxima dos valores encontrados na literatura nacional para o 'sistema um ano', em condições de alimentação similares às deste estudo (Rocha \& Lobato, 2002).

No entanto, segundo Beretta et al. (2001), a produtividade máxima em sistemas de ciclo completo depende da taxa de natalidade do rebanho adulto e, no 'sistema um ano' a máxima eficiência é alcançada com taxa geral de $92 \%$. Taxa compatível com alta produtividade em acasalamento aos 13/15 meses de idade foi determinado por Pilau \& Lobato (2008) em experimento com taxa de prenhez de $92 \%$. 
Tabela 7 - Coeficientes de correlação entre pesos ao desmame à idade convencional (DC) e pesos ao início (IPR) e fim (FPR) do período reprodutivo, condição corporal ao início (CCIPR) e fim (CCFPR) do período reprodutivo, ganho de peso médio diário durante o período reprodutivo (GMDPR) e porcentagem de prenhez entre 13 e 15 meses (PP13) de novilhas de corte

\begin{tabular}{|c|c|c|c|c|c|c|c|}
\hline & $\mathrm{DC}$ & IPR & FPR & CCIPR & CCFPR & GMDPR & PP 13 \\
\hline DC & - & $0,7746^{* *}$ & $0,7665 * *$ & $0,5426 * *$ & $0,5062 * *$ & $0,2642 * *$ & $0,3662 * *$ \\
\hline IPR & - & - & $0,9602 * *$ & $0,6209 * *$ & $0,5745^{* *}$ & $0,2156^{*}$ & $0,3200 * *$ \\
\hline FPR & - & - & - & $0,6711 * *$ & $0,6433 * *$ & $0,4753 * *$ & $0,3112 * *$ \\
\hline CCIPR & - & - & - & - & $0,9236 * *$ & $0,4779 * *$ & $0,2268^{*}$ \\
\hline CCFPR & - & - & - & - & - & $0,5463 * *$ & $0,2106^{*}$ \\
\hline GMDPR & - & - & - & - & - & - & 0,096 \\
\hline PP 13 & - & - & - & - & - & - & - \\
\hline
\end{tabular}

$* * \mathrm{P}<0,01 ; * \mathrm{P}<0,05$

\section{Conclusões}

Novilhas desmamadas aos 77 dias de idade não diferem em desenvolvimento de novilhas desmamadas à idade convencional de 147 dias, portanto, podem ser submetidas ao primeiro período reprodutivo entre os 13 e 15 meses de idade com pesos, condições corporais e fertilidade semelhantes, desde que tenham condições adequadas de alimentação e manejo. Novilhas com diagnóstico de prenhez positivo aos 13/15 meses de idade são mais pesadas, mais velhas e têm melhor condição corporal e melhores ganhos de peso do nascimento até o final do acasalamento em comparação a novilhas não-prenhes. Recomenda-se a realização de novos estudos, tendo em vista o pequeno número de animais utilizados no experimento.

\section{Referências}

ALBOSPINO, B.H.J.C.; LOBATO, J.F.P. Efeitos do desmame precoce de bezerras no desempenho até os 24-26 meses de idade. Revista Brasileira de Zootecnia, v.22, n.6, p. $1033-1043,1993$.

ALLDEN, W.G. Energy andprotein supplementation for grazing livestock. In: MORLEY, F.H.W. (Ed.) Grazing animals. Amsterdam: Elsevier, 1981. 411p.

ALMEIDA, L.S.P.; LOBATO, J.F.P. Data de desmame e desempenho reprodutivo de vacas de corte. Revista Brasileira de Zootecnia, v.31, n.3, p.1223-1229, 2002.

ALMEIDA, L.S.P.; LOBATO, J.F.P. Efeito da idade de desmame e suplementação no desenvolvimento de novilhas de corte. Revista Brasileira de Zootecnia, v.33, n.6, p.2086-2094, 2004 (supl.2).

ALMEIDA, L.S.P.; LOBATO, J.F.P.; SCHENKEL. F.S. Idade de desmame e suplementação no desenvolvimento e características de carcaças de novilhos de corte. Revista Brasileira de Zootecnia, v.32, n.6, p.1713-1721, 2003 (supl.1)

ARIJE, G.F.; WILTBANK, J.N. Age and weight at puberty in Hereford heifers. Journal of Animal Science, v.33, n.2, p.401-406, 1971.

ASSOCIATION OF OFFICIAL ANALYTICAL CHEMITS - AOAC. Official methods of analysis. 14.ed. Washington, D.C.: AOAC Internacional, 1984. 1141p.

BARCELLOS, J.O.J.; LOBATO, J.F.P.; FRIES, L.A. Desempenho reprodutivo de vacas primíparas Hereford e Mestiças Nelore-
Hereford com estação de parição e monta no outono/inverno ou primavera/verão. Revista Brasileira de Zootecnia, v.26, n.5, p.976-985, 1997.

BERETTA, V.; LOBATO, J.F.P. Sistema "um ano" de produção de carne: avaliação de estratégias alternativas de alimentação hibernal de novilhas de reposição. Revista Brasileira de Zootecnia, v.27, n.1, p.157-163, 1998.

BERETTA, V.; LOBATO, J.F.P.; MIELitZ NETO, C.G.A Produtividade e eficiência biológica de sistemas pecuários de cria diferindo na idade das novilhas ao primeiro parto e na taxa de natalidade do rebanho no Rio Grande do Sul. Revista Brasileira de Zootecnia, v.20, n.4, p.1278-1286, 2001.

BERETTA, V.; LOBATO, J.F.P.; MIELITZ NETO, C.G.A Produtividade e eficiência biológica de sistemas de produção de gado de corte de ciclo completo no Rio Grande do Sul Revista Brasileira de Zootecnia, v.31, n.2, p.991-1001, 2002 (supl.).

BITTENCOURT, H.R.; GOTTSCHALL, C.S.; SANT'ANA, M.F. Um modelo alternative para a predição da probabilidade de prenhez em função do peso ao início do acasalamento. Arquivos de Ciências Veterinárias e Zoologia, v.8, n.2, p.99-104, 2005.

BYERLEY, D.J.; STAIGMILLER, R.B.; BERARDINELLI, J.G. et al. Pregnancy rates of beef heifers bred either on puberal or third estrus. Journal of Animal Science, v.65, n.5, p.645-650, 1987.

CUNDIFF, L.V.; GREGORY, K.E. WHEELER, T.L. et al. Germplasm evaluation program progress report. Clay Center, 2000. 12p. (Agricultural Research Service, 19)

EMPRESA BRASILEIRA DE PESQUISA AGROPECUÁRIA EMBRAPA. Sistema brasileiro de classificação de solos. Brasília: Embrapa Cerrados; Rio de Janeiro: Centro Nacional de Pesquisa de Solos, 1999. 412p.

FAGUNDES, J.I.B.; LOBATO, J.F.P.; SCHENKEL, F.S. Efeito de duas cargas animais em campo nativo e de duas idades a desmama no desempenho de vacas de corte primíparas. Revista Brasileira de Zootecnia, v.32, n.6, p.1722-1731, 2003 (supl.1).

FRIES, L.A. Genética para um sistema de produção de ciclo curto In: SIMPÓSIO DA CARNE BOVINA: da produção ao mercado consumidor, 2003, São Borja, RS. Anais... Porto Alegre: Ed. UFRGS, 2003. p.47-82.

FRIES, L.A. Critérios de seleção para um sistema de produção de ciclo curto. In: SEMINÁRIO DE AVALIAÇÃO DE BOVINOS DE CORTE E FORMAÇÃO DO CORPO DE JURADOS DA RAÇA ANGUS, 1., 2004, Esteio. Anais... Porto Alegre: Associação Brasileira de Criadores de Angus, 2004. p.74-88.

FUNSTON, R.N.; DEUSTSCHER, G.H. Comparation of target breeding weight and breeding date for replacement beef heifers and effects on subsequent reproduction and calf performance. Journal of Animal Science, v.82, n.12, p.3094-3099, 2004.

HAYDOCK, K.P.; SHAW, N.H. The comparative yield method for stimating dry matter yield of pasture. Australian Journal of Experimental Agriculture and Animal Husbandry, v.15, n.76, p.663-670, 1975 . 
INSTITUTO BRASILEIRO DE GEOGRAFIA E ESTATÍSTICA IBGE. Censo agropeucario 2006. Rio de Janeiro, 2006. 146p.

KINDER, J.E.; ROBERSON, M.S.; WOLFE, M.W. et al. Management factors affecting puberty in the heifer. In: FIELDS, M.J.; SAND, R.S. (Eds.) Factors affecting calf crop. Boca Raton: CRC Press, 1994. p.69-89.

LESMEISTER, J.L.; BURFENING, P.J.; BLACKWELL, R.L. Date of first calving in beef cows and subsequent calf production. Journal of Animal Science, v.36, n.1, p.1-6, 1973.

LOBATO, J.F.P.; ALMEIDA, L.S.P.; OSÓRIO, E.B. et al. Efeito da idade de desmame no desenvolvimento e características de carcaça de novilhos de corte. Revista Brasileira de Zootecnia, v.36, n.3, p.596-602, 2007.

LOBATO, J.F.P.; BARCELLOS, J.O.J. Efeito da utilização de pastagem melhora no pós-parto e do desmame aos 100 ou 180 dias de idade no desempenho reprodutivo de vacas de corte. Revista Brasileira de Zootecnia, v.21, n.3, p.385-395, 1992.

LOBATO, J.F.P.; MAGALHÃES, F.R. Comportamento reprodutivo de primíparas aos 24 e 36 meses de idade. Arquivos da Faculdade de Veterinária UFRGS, v.29, n.2, p.139-146, 2001.

LOBATO, J.F.P.; MÜLLER, A.; PEREIRA NETO, O.A. et al. Efeitos da idade à desmama sobre o desempenho reprodutivo de vacas de corte primíparas. Revista Brasileira de Zootecnia, v.29, n.6, p.2013-2018, 2000 (supl.1).

LOWMAN, B.G.; SCOTT, N.; SOMERVILlE, S. Condition scoring beef cattle. Edinburgh: East of Scotland College of Agriculture. 1973. 8p

MORAES, A.A.S.; LOBATO, J.F.P. Efeito de duas idades de desmame no desenvolvimento de terneiros de corte. Revista Brasileira de Zootecnia, v.22, n.6, p.885-892, 1993.

MOOJEN, J.G.; RESTLE, J.; MOOJEN, E.L. Efeito da época de desmama e da pastagem no desempenho de vacas e terneiros de corte. 1. Desempenho das vacas. Ciência Rural, v.24, n.2, p.393-397, 1994

MORENO, J.A. Clima do Rio Grande do Sul. Porto Alegre: Secretaria da Agricultura, 1961. 41p.

MORRIS, C.A. A review of relationships between aspects of reproduction in beef heifers and their lifetime production. 1 . Associations with fertility in the first joining season and age at first joining. Animal Breeding Abstract, v.48, p.655-667, 1980.

NATIONAL RESEARCH COUNCIL - NRC. Nutrient requeriment of beef cattle. Washington D.C.: National Academy Press, 1996. 244p

PATERSON, D.J.; PERRY, R.C.; KIRAKOFE, G.H. et al. Management considerations in heifers development and puberty. Journal of Animal Science, v.70, n.12, p.4018-4035, 1992.

PEREIRA NETO, O.A.; LOBATO, J.F.P.; Efeitos da ordem de utilização de pastagens nativas melhorada no desenvolvimento e comportamento reprodutivo de novilhas de corte. Revista Brasileira de Zootecnia, v.27, n.1, p.60-65, 1998.

PILAU,A.; LOBATO, J.F.P.; Recria de bezerras com suplementação no outono e pastagem cultivada no inverno. Revista Brasileira de Zootecnia, v.35, n.6. p.2388-2396, 2006.

PILAU, A.; LOBATO, J.F.P.; Manejo de novilhas prenhes aos 13/15 meses de idade em sistemas a pasto. Revista Brasileira de Zootecnia, v.37, n.7, p.1271-1279, 2008.

PÖTTER, B.A.A.; LOBATO, J.F.P. Desempenho e características quantitativas de carcaças de novilhos Braford desmamados aos 100 ou 180 dias de idade abatidos aos 13-14 meses. Revista Brasileira de Zootecnia, v.32, n.5, p.1220-1226, 2003.

PÖTTER, L.; LOBATO, J.F.P.; MIELITZ NETO, C.G.A. Produtividade de um modelo de produção para novilhas de corte primíparas aos dois, três e quatro anos de idade. Revista Brasileira de Zootecnia, v.27, n.3, p.613-619, 1998.

PÖTTER, L.; LOBATO, J.F.P.; MIELITZ NETO, C.G.A. Análises econômicas de modelos de produção com novilhas de corte primíparas aos dois, três ou quatro anos de idade. Revista Brasileira de Zootecnia, v.29, n.3, p.861-870, 2000.

RESTLE, J.; POLLI, V.A.; ALVES FILHO, D.C. et al. Desenvolvimento de bovinos de corte de diferentes grupos genéticos desmamados aos 3 ou 7 meses de idade. Revista Brasileira de Zootecnia, v.28, n.5, p.1023-1030, 1999a.

RESTLE, J.; POLLI, V.A.; SENNA, D.B. Efeito de grupo genético e heterose sobre a idade e peso a puberdade e sobre o desempenho reprodutivo de novilhas de corte. Pesquisa Agropecuária Brasileira, v.34, n.4, p.701-707, 1999b.

RESTLE, J.; VAZ, R.Z.; ALVES FILHO, ID.C. et al. Desempenho de vacas Charolês e Nelore desterneiradas aos três ou sete meses. Revista Brasileira de Zootecnia, v.30, n.2, p.499-507, 2001.

ROCHA, M.G.; LOBATO, J.F.P.; Avaliação do desempenho reprodutivo de novilhas de corte primíparas aos dois anos de idade. Revista Brasileira de Zootecnia, v.31, n.3, p.1388-1395, 2002 (supl).

ROCHA, M.G.; PILAU, A.; SANTOS, D.T. et al. Desenvolvimento de bezerras de corte submetidas a diferentes sistemas de alimentares. Revista Brasileira de Zootecnia, v.33, n.6, p.2123-2131, 2004 (supl. 2).

ROVIRA, J.M. Manejo nutritivo de los rodeos de cria em pastoreo. Montivideo: Hemisfério Sur, 1996. 288p.

SAMPAIO, I.B.M. Estatística aplicada à experimentação animal. 1.ed. Belo Horizonte: Fundação de Ensino e Pesquisa em Medicina Veterinária e Zootecnia, 1998. v.1, 221p.

SCHILLO, K.K. Effects of dietary energy on control of luteinizing hormone secretion in cattle and sheep. Journal of Animal Science, v.70, n.12, p.1271-1282, 1992.

SHORT, R.E.; BELLOWS, R.A. Relathionship among weight gains, age at puberty and reproductive performance in heifers. Journal of Animal Science, v.32, n.5, p.1964-1970, 1971.

SHORT, R.E.; STAIMILLER, R.B.; BELLOWS, R.A. et al. Breeding heifers at one year of age: Biological and economic considerations. In: FIELDS, M.J.; SAND, R.S. Factors affecting calf crop. London: CRC Press, 1994. p.55-68.

SIMEONE, A.; LOBATO, J.F.P. Efeitos da lotação animal em campo nativo e do controle da amamentação no comportamento reprodutivo de vacas de corte primíparas. Revista Brasileira de Zootecnia, v.25, n.6, p.1216-1227, 1996.

STATISTICAL ANALYSIS SYSTEM - SAS. SAS/STAT user's guide: statistics. 4.ed. Version 6. Cary: 1997. v.2, 943p.

VAN SOEST, P.J. Nutritional ecology of the ruminant. 2.ed. Ithaca: Cornell University Press 1944. 476p

VAZ, R.Z.; RESTLE, J. Níveis de suplementação para novilhas durante o primeiro período reprodutivo dos 14 aos 17 meses II. Desempenho Reprodutivo. In: REUNIÃO ANUAL DA SOCIEDADE BRASILEIRA DE ZOOTENIA, 37., 2000, Viçosa, MG. Anais... Viçosa, MG: Sociedade Brasileira de Zootecnia, 2000a.

VAZ, R.Z.; RESTLE, J. Níveis de suplementação para novilhas durante o primeiro período reprodutivo dos 14 aos 17 meses I. Desenvolvimento ponderal. In: REUNIÃO ANUAL DA SOCIEDADE BRASILEIRA DE ZOOTENIA, 37., 2000 , Viçosa, MG. Anais... Viçosa, MG: Sociedade Brasileira de Zootecnia, 2000b.

WEEKLEY, K.A.; MARSHALL, T.T.; HARGROVE, D.D. Effects of nutritional environment on percentage of mature weight at which crossbred heifers of varying proportion of Brahman breeding attain puberty. In: ANNUAL FLORIDA BEEF CATTLE SHORT COURSE, 42., 1993, Gainesville. Proceeding... Gainesville: University of Florida, 1993. p.54-59.

WILTBANK, J.N.; ROBERTS, J.N.; ROWDEN, L. Reproductive performance and profitability of heifers feed to weight 272 or $318 \mathrm{~kg}$ at the start of the first breeding season. Journal of Animal Science, v.60, n.1, p.25-35, 1985. 